\title{
Lennox-Gastauts syndrom - forløp og behandling
}

\author{
Sammendrag \\ Bakgrunn. Lennox-Gastauts syndrom \\ er en alvorlig epileptisk encefalopati \\ som starter i førskolealder med flere \\ anfallstyper. Barna utvikler kognitiv \\ svikt og et typisk EEG-mønster. \\ Hensikten med denne artikkelen er \\ å beskrive det kliniske sykdomsbildet, \\ med særlig vekt på hvordan det går \\ med disse barna i voksen alder.
}

Materiale og metode. Artikkelen er basert på et ikke-systematisk søk i PubMed frem til november 2009 og våre egne kliniske erfaringer.

Resultater. Det finnes former av Lennox-Gastauts syndrom med uklar etiologi og symptomatiske former med et bredt spekter av bakenforliggende årsaker. Mens barn med syndromet har høy frekvens av hovedsakelig generaliserte anfallsformer, kan anfallsaktiviteten avta noe i voksen alder, samtidig som mange utvikler fokale anfall. Prognosen er ofte dyster. Den voksne pasienten er ofte sløvet og apatisk, preget av sin globale encefalopati med progredierende kognitiv og motorisk funksjonssvikt. Valproat har i mange år vært selve grunnbehandlingen. Nyere antiepileptika, som lamotrigin, topiramat og rufinamid, har vist effekt som tilleggsbehandling. Overbehandling med antiepileptika er vanlig.

Fortolkning. I alle aldre må pasienter med Lennox-Gastauts syndrom følges opp av spesialist for å få optimal behandling. Nye behandlingsformer med mindre bivirkninger kan gi mennesker med Lennox-Gastauts syndrom bedre livskvalitet.

\section{Caroline Lund}

caroline.lund@epilepsy.no

Avdeling for kompleks epilepsi (SSE)

Oslo universitetssykehus

Postboks 53

1306 Bærum postterminal

\section{Eylert Brodtkorb}

Avdeling for nevrologi og nevrofysiologi

St. Olavs hospital

og

Institutt for nevromedisin

Norges teknisk-naturvitenskapelige universitet

\section{Karl 0. Nakken}

Avdeling for kompleks epilepsi

Oslo universitetssykehus

Blant epilepsiformene er Lennox-Gastauts syndrom en av de mest alvorlige. Syndromet debuterer i barneårene, pasientene har hyppige anfall, ofte med plutselige fall, liten effekt av antiepileptika og utvikler kognitiv svikt. Selv om syndromet har relativt karakteristiske kliniske og nevrofysiologiske trekk, kan grenseoppgangen mot andre alvorlige epilepsiformer være vanskelig. Kunnskapen om det kliniske forløpet i voksen alder har vært mangelfull. I denne artikkelen gir vi en kort oversikt over syndromet og beskriver hvordan tilstanden kan arte seg hos barn og voksne.

\section{Materiale og metode}

Artikkelen er basert på et ikke-systematisk søk i PubMed frem til november 2009 samt våre mangeårige kliniske erfaringer med pasientgruppen ved Avdeling for kompleks epilepsi (SSE) ved Oslo universitetssykehus og ved Avdeling for nevrologi og nevrofysiologi ved St. Olavs hospital i Trondheim.

\section{Historikk og definisjon}

EEG-forstyrrelsene ved Lennox-Gastauts syndrom ble beskrevet av Gibbs i 1938, mens Lennox sto sentralt $\mathrm{i}$ beskrivelsen av det kliniske korrelatet til dette EEG-mønsteret (1). Senere har flere, fremfor alt Gastaut, bidratt til en tydeligere avgrensning av det elektrokliniske bildet (2). Siden 1966 har man brukt betegnelsen Lennox-Gastauts syndrom.

I litteraturen er det ingen allmenn enighet om de diagnostiske kriteriene, men i hovedsak brukes de som er angitt i ramme 1 (3). Betegnelsen Lennox-Gastauts syndrom blir av noen benyttet hos pasienter med en epilepsi som debuterer i barneårene og som ytrer seg ved flere anfallstyper, men som ikke har de typiske EEG-forstyrrelsene. Vi er enig med dem som mener dette er galt og har foreslått å benytte betegnelsen «Lennox-Gastauts syndrom-liknende» om slike tilstander.

De fleste er enige om at det må være minst to generaliserte anfallstyper og langsomt pigg-bølge-mønster (spike-wave-aktivitet) $(<2,5 \mathrm{~Hz})$ ved EEG i våken tilstand (fig 1) for å kunne stille diagnosen Lennox-Gastauts syndrom. I tillegg kreves forsinket eller stagnert psykomotorisk utvikling og at anfallene er farmakoresistente. Enkelte hevder at toniske anfall og nattlig rask epileptiform aktivitet i EEG (fig 2) også er obligatorisk (3).

Noen mener at det finnes en myoklonisk variant av Lennox-Gastauts syndrom med særlig fremtredende myoklonier, mens andre hevder at dette trolig er pasienter med en annen epilepsiform, nemlig myoklon astatisk epilepsi, også kalt Dooses syndrom (4).

Lennox-Gastauts syndrom er selve prototypen av en epileptisk encefalopati, der den hissige epileptiske aktiviteten forårsaker og/ eller forsterker den kognitive svikten.

\section{Epidemiologi}

Epidemiologiske data er noe sprikende, trolig som en følge av at forfatterne har brukt ulike diagnostiske kriterier. Tilstanden debuterer i $1-8$ års alder, med en topp rundt $3-5$ år. Gutter er hyppigere affisert enn jenter (3). Fra Finland er det rapportert en årlig insidens på 2 per 100000 barn i alderen 0 - 14 år (5). Prevalensen er anslått til 3-4\% av alle epilepsiene, $4-8 \%$ av epilepsiene blant barn under ti år, og ca. $10 \%$ av de refraktære epilepsiene $(3,6,7)$. I en epidemiologisk studie av barn med epilepsi i alderen 6-12 år på Vestlandet fant Waaler og medarbeidere at $4 \%$ av barna hadde Lennox-Gastauts syndrom (8). Rundt $4 \%$ av pasienter med psykisk utviklingshemning og epilepsi har Lennox-Gastauts syn-

\section{Hovedbudskap}

- Lennox-Gastauts syndrom er et alvorlig epilepsisyndrom som kjennetegnes av flere typer epileptiske anfall og kognitiv svikt

- Syndromet debuterer i førskolealder med toniske og atoniske anfall, mens fokale anfall kan komme i voksen alder

- Farmakoterapi er utfordrende, men nye behandlingsformer kan gi en bedre balanse mellom effekt og bivirkninger 
drom, mens forekomsten ifølge Forsgren er nærmere $10 \%$ dersom man bruker utvidede diagnostiske kriterier (9).

\section{Etiologi}

Årsaken til tilstanden er viktig for prognosen. Hos pasienter uten kjent årsak er prognosen noe bedre enn blant dem med symptomatisk Lennox-Gastauts syndrom. Bak de symptomatiske formene er det mange årsaker, for eksempel kortikale misdannelser, pre-, perieller postnatale hjerneskader (hypoksisk iskemi, infeksjoner, traumer), hjernesvulster og genetiske tilstander som tuberøs sklerose. Hos pasienter uten strukturell eller metabolsk årsak er det foreløpig ikke holdepunkter for predisponerende genetiske faktorer, men ved Lennox-Gastauts syndrom-liknende tilstander er det nylig funnet mutasjoner i natriumkanalgenet SCN1A (10).

De patofysiologiske mekanismene bak utviklingen av denne diffuse encefalopatien er ikke fullt ut forstått. Muligens skjer det hos disse barna en forstyrret synaptogenese med påfølgende økt nevronal eksitabilitet. Den epileptiske aktiviteten antas å forsterke en slik prosess, som i en hjerne under utvikling kan få katastrofale følger.

\section{Klinisk bilde hos barn}

Hos 20-30\% starter de epileptiske anfallene hos et tidligere friskt barn - uten noen kjent årsak til anfallene (7). Hos de resterende finnes en bakenforliggende årsak, og mange av disse barna har allerede før debut av sin epilepsi nevrologiske utfall, forsinket kognitiv utvikling og/eller atferdsvansker (symptomatisk form). Lennox-Gastauts syndrom kan utvikle seg fra andre epilepsiformer, og rundt $20 \%$ av barna har tidligere hatt Wests syndrom med infantile spasmer (11). Nesten halvparten av barn med symptomatisk Wests syndrom utvikler LennoxGastauts syndrom senere (12).

\section{Anfallstyper}

Toniske anfall er den vanligste anfallsformen og opptrer hos 70-90\% (3). Anfallene er av kort varighet, 2-10 sekunder, de opptrer som oftest om nettene, og de kan være så subtile at de ikke oppdages ved klinisk observasjon. Pasienten kan plutselig løfte hodet fra puten, øynene åpnes, øyebrynene heves, og eventuelt åpnes munnen til et fiksert smil. Av og til høres et lite skrik. Noen toniske anfall er kraftigere: det kommer en aksial tilstivning; nakken og overkroppen bøyes, skuldre og armer heves i en semiflektert stilling, beina ekstenderes, pupillene dilateres, og ofte er det ledsagende apné og urinavgang. I stående stilling opptrer fall, og mange skader seg. Anfallene kan være enkeltstående eller komme i serier, og bevisstheten tapes ikke alltid (13).

Atoniske eller astatiske anfall opptrer hos ca. $50 \%$ (3). Anfallene består av plutselig tap av muskeltonus og involverer enten kun hodet eller hele kroppen. Atoniske anfall ble lenge ansett som den vanligste årsak til fall og skader (drop attacks), særlig av hode og tenner, men enkelte studier viser at de plutselige fallene oftere skyldes toniske anfall enn atoniske $(14,15)$. Bevisstheten er ikke affisert, og pasienten reiser seg opp med en gang etter anfallet.

Atypiske absenser opptrer hos de aller fleste, og klinisk kan disse anfallene være vanskelig å oppdage (16). I motsetning til typiske absenser starter og slutter disse anfallene gradvis, de varer gjerne flere minutter, og bevisstheten er bare delvis nedsatt. Pasienten kan eksempelvis fortsette å utføre sine aktiviteter, men $i$ et nedsatt tempo. Ofte ses en endret kroppstonus og diskrete myoklonier. Sikker diagnose stilles ved anfallsregistrering på EEG der det ses et langsomt $(<2,5 \mathrm{~Hz})$ pigg-bølge-mønster.

Myoklonier opptrer hos 10-30\% (1) og består av svært korte, ofte bilaterale rykk. Myoklonier kan opptre sammen med atoniske anfall (myoklonisk-atoniske anfall) og forårsaker da gjerne fall (7).

Status epilepticus forekommer hos de fleste med syndromet (3). Hyppigst ses ikkekonvulsiv status epilepticus i form av vedvarende atypiske absenser. Tilstanden kan vare dager eller uker og kan være vanskelig både å oppdage og behandle, spesielt fordi EEG under ikke-konvulsiv status epilepticus kan være nokså likt pasientens interiktale EEG. Det generaliserte pigg-bølge-mønsteret er gjerne noe mer fremtredende, og vanligvis er EEG-funnene generelt mer patologisk (16).

Status av toniske, atoniske, myoklone og tonisk-kloniske anfall forekommer også.

Fokale anfall og generaliserte tonisk-kloniske anfall er ikke uvanlig ved Lennox-

\section{Ramme 1}

\section{Trekk ved Lennox-Gastauts syndrom}

Følgende anfallstyper kan foreligge i en kombinasjon:

- Atypiske absenser

- Atoniske anfall

- Toniske anfall

- Myoklonier

- Generaliserte tonisk-kloniske anfall

- Fokale anfall (særlig i voksen alder)

Vanlige EEG-funn:

- I våken tilstand: Langsomt $(<2,5 \mathrm{~Hz}$ ) generalisert pigg-bølge-mønster (fig 1)

- Under søvn: Utbrudd av rask paroksysmal aktivitet (fig 2)

Gastauts syndrom, men slike anfall er ikke spesielt knyttet til denne tilstanden.

\section{Utredning}

Som ved andre epilepsiformer står anamnese, klinisk nevrologisk undersøkelse, EEG og cerebral MR sentralt i utredningen. EEGregistrering gjennom en natt er viktig for å fange opp utbrudd av rask epileptiform aktivitet under søvn. For å kunne gjennomføre MR-undersøkelse er narkose ofte nødvendig. Genetisk utredning må utføres når kliniske tegn tilsier det, for eksempel ved mistanke om tuberøs sklerose.

\section{Differensialdiagnostikk}

Aktuelle differensialdiagnoser er myoklonusepilepsi i barneårene, epilepsi med kon-

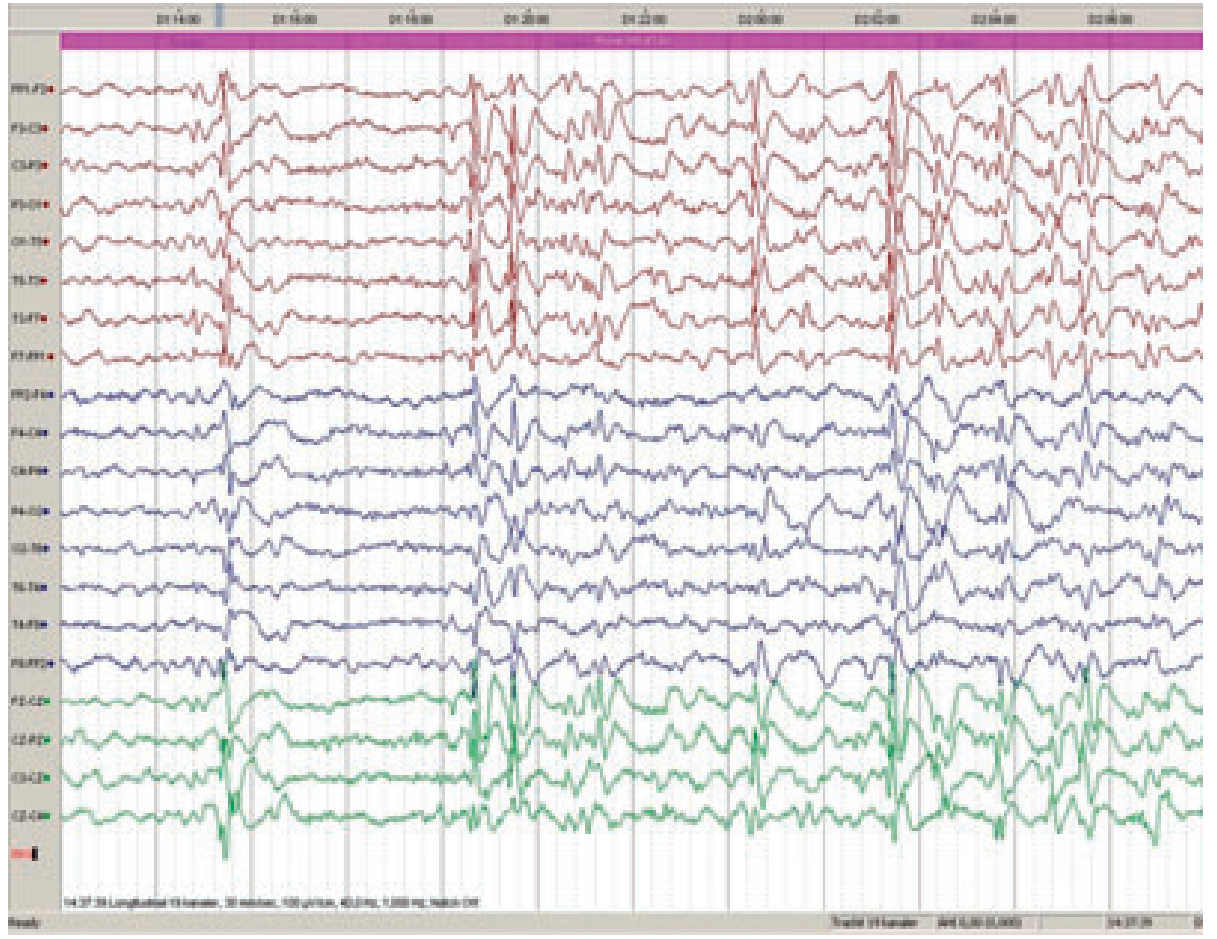

Figur 1 Utbrudd av langsomt generalisert pigg-bølge-mønster i EEG hos en våken pasient med Lennox-Gastauts syndrom 


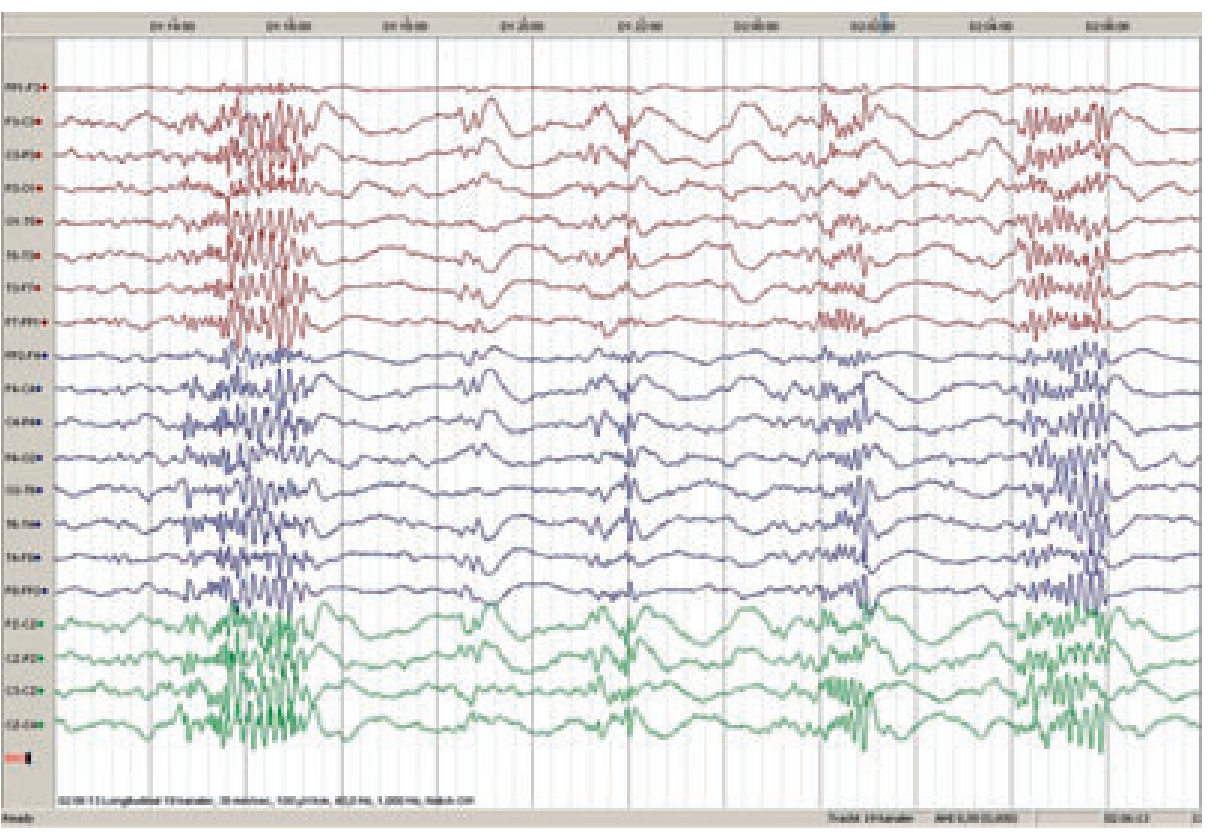

Figur 2 EEG tatt under søvn hos en pasient med Lennox-Gastauts syndrom viser utbrudd av rask paroksysmal EEG-aktivitet (runs of rapid spikes)

tinuerlig pigg-bølge-mønster under dyp søvn, Angelmans syndrom, Dravets syndrom og andre nevrodegenerative tilstander. Myoklon astatisk epilepsi (Dooses syndrom) (4) har mange likhetstrekk med Lennox-Gastauts syndrom, men myokloniene er mer fremtredende, og prognosen er bedre, idet bare ca. $50 \%$ blir utviklingshemmede. Dravets syndrom bør særlig overveies dersom anfallene har startet $\mathrm{i}$ første leveår og har vært utløst av feber.

\section{Prognose}

Lennox-Gastauts syndrom blir klassifisert blant de mest alvorlige epilepsiformene på grunn av den dårlige prognosen. Anfallstendensen varierer; dårlige perioder avløses av bedre perioder. I perioder med hyppige anfall fungerer pasientene ofte kognitivt dårlig. $80-90 \%$ av dem som når voksen alder fortsetter å ha anfall. Ca. $90 \%$ får et betydelig nedsatt kognitivt funksjonsnivå, og mange utvikler ekstrapyramidale og cerebellare utfall i form av gangvansker, dysfagi, sikling og dysartri $(17,18)$. Mortaliteten er høy, og tidlig død skyldes som oftest status epilepticus, ulykker eller interkurrente sykdommer. Nær $10 \%$ av barna dør før 11 års alder (19). Prognosen er best hos pasienter med normal utvikling frem til anfallsstart og som ikke har et morfologisk substrat i hjernen.

\section{I voksen alder}

Selv om anfallsfrekvensen som regel avtar noe i puberteten, vil $^{2} / 3$ fortsatt ha daglige eller ukentlige anfall ti år etter anfallsdebut (20). Ca. $10 \%$ blir helt kvitt anfallene i voksen alder (21). Voksne pasienter med vedvarende lav mental alder fortsetter vanligvis å ha toniske og atoniske anfall (12), mens atypiske absenser iblant avløses av partielle anfall med eller uten sekundær generalisering (22).
Hos rundt $1 / 3$ av dem der årsaken er ukjent og rundt halvparten av dem der tilfellene er symptomatiske, vil de karakteristiske EEGforstyrrelsene bli borte i voksen alder (3). EEG viser gjerne mer uspesifikke generaliserte, multifokale eller fokale forstyrrelser (20). Ca. $90 \%$ av pasientene vil med årene få en tiltakende intellektuell svikt (3). Opptil $50 \%$ utvikler ulike nevrologiske utfall, bl.a. uttalt ataksi med gangvansker $(20,23)$. Det kan være mange årsaker til de progredierende utfallene, for eksempel en tilgrunnliggende lesjon, hyppig subklinisk epileptisk aktivitet, høy anfallsfrekvens, gjentatte hodeskader, mange episoder med status epilepticus (særlig hvis disse opptrer i ung alder) og nevrotoksiske effekter av antiepileptika.

Gangvansker og anfall der personen plutselig faller om (drop attacks) kan i voksen alder være så invalidiserende at man blir avhengig av rullestol. Hyperaktivitet, aggresjon og autistiske trekk kan vedvare, men perseverasjon, langsomhet og apati er ofte mer fremtredende. Forstyrret døgnrytme er ofte et stort problem. Kun få vil være i stand til å leve selvstendig, og de fleste bor i kommunale omsorgsboliger. Inaktivitet og understimulering, ofte som ledd i utilstrekkelige miljøtiltak, kan bidra til en negativ utvikling (24).

\section{Behandling}

\section{Profylaktisk medikamentell behandling}

Valproat har lenge vært grunnbehandlingen ved Lennox-Gastauts syndrom. Medikamentet har erfaringsmessig effekt ved multiple generaliserte anfallsformer. Formaliserte studier av valproat er pussig nok aldri blitt utført ved denne tilstanden, selv om ingen andre epilepsisyndromer har vært gjenstand for så mange randomiserte, kontrollerte multisenterstudier med nyere antiepileptika. Det er vist at felbamat, lamotrigin, topiramat og ru- finamid har anfallsreduserende effekt ved Lennox-Gastauts syndrom (25-27), og flere andre bredpektrede antiepileptika (levetiracetam, zonisamid, benzodiazepiner) kan være verdt å forsøke selv om disse ikke er prøvd ut i randomiserte studier. Smalspektrede antiepileptika som karbamazepin og fenytoin bør unngås fordi disse medikamentene kan forverre anfallssituasjonen i denne pasientgruppen (28). Fenytoin kan medføre utvikling av fenytoinencefalopati med økt kognitiv svikt og ataksi (28). Døsighet indusert av legemidler med sedativ effekt, som for eksempel fenobarbital, kan også forverre anfallssituasjonen (25). Det er et problem at de stadige svingningene $i$ anfallstendens og atferd kan gjøre det vanskelig å vurdere effekten av ulike behandlingsforsøk.

Ved Lennox-Gastauts syndrom kan det være en utfordring å finne en optimal balanse mellom anfallsreduksjon og bivirkninger. Ofte er det nødvendig å bruke en kombinasjon av flere medikamenter. På grunn av den sterke anfallstendensen ender mange opp med en svært tung multimedikasjon. Dette til tross for at disse pasientene ofte er mer sårbare for bivirkninger enn andre epilepsipasienter. Det hender at pasientens livskvalitet er mer påvirket av medikamentelle bivirkninger enn av selve anfallene. Anfallene er ofte farmakoresistente, og anfallsreduksjon bør ikke være målet for enhver pris. Vår erfaring er at overbehandling er vanligere enn underbehandling, særlig i voksen alder. Uhensiktsmessig behandling med antiepileptika som vanligvis ikke har god effekt ved denne epilepsiformen, bør unngås. Toleranseutvikling er et vanlig problem, slik at medikamentene etter en tid mister sin effekt. Det vil i enkelte situasjoner kunne være aktuelt å forsøke å fjerne ett eller flere medikamenter, noe som vil kunne medføre en forbigående anfallsøkning.

\section{Anfallskuperende behandling}

Ved langvarige anfall, serieanfall og begynnende status epilepticus får mange av disse pasientene benzodiazepiner rektalt (Stesolid) eller bukkalt (Epistatus) for å bryte anfallsaktiviteten. Med en stor andel ufaglærte i omsorgsboligene er det vår erfaring at det fort kan oppstå et overforbruk av slike medikamenter. Toleranseutvikling kan opptre, og en svingende konsentrasjon av benzodiazepiner i blodet kan bidra til nye anfallsperioder pga. abstinens. Dette kan bringe disse pasientene inn i en ond sirkel som først kan brytes ved sykehusinnleggelse (29). Det bør utarbeides skriftlige prosedyrer for anfallskupering for hver enkelt pasient.

Man bør også være oppmerksom på at benzodiazepiner hos enkelte kan fremkalle toniske anfall i form av en paradoks effekt ved dette syndromet.

\section{Ikke-farmakologisk behandling}

På grunn av mer eller mindre generalisert eller multifokal epileptisk aktivitet er resek- 
tiv kirurgi sjelden aktuelt. Hos noen barn med symptomatiske former kan en tidlig lesjonektomi stoppe den uheldige utviklingen. Hos de særlig skadeutsatte pasientene med hyppige atoniske og toniske anfall kan overskjæring av fremre $2 / 3$ av corpus callosum (callosotomi) være aktuelt (3). Dette er et palliativt inngrep som tar sikte på å hindre spredning av den epileptiske aktiviteten transcallosalt. Pasientene blir sjelden anfallsfrie, men får gjerne en betydelig reduksjon av de atoniske anfallene (30).

Også intermitterende elektrisk stimulering av vagusnerven kan gi en bedret anfallssituasjon (31), og hos pasienter med invalidiserende atoniske anfall anbefaler vi å forsøke slik behandling før man tyr til callosotomi. Videre kan ketogen diett gi bedring av anfallssituasjonen, særlig blant barn (24). Ernæringssituasjonen må da overvåkes.

Søvnighet og inaktivitet, enten naturlig eller som en bivirkning av antiepileptika, kan senke anfallsterskelen (24). Det er derfor viktig at disse pasientene aktiviseres ved for eksempel skole, dagsenter eller vernet arbeidsplass. For å beskytte mot hode- og ansiktsskader kan bruk av hjelm være nyttig.

For pasienter med forstyrret søvnrytme bør man forsøke å forbedre søvnhygiene etter vanlige retningslinjer. Hos enkelte kan også melatonin være til hjelp.

\section{Konklusjon}

Lennox-Gastauts syndrom er en svært behandlingsresistent epilepsiform med mange bakenforliggende årsaker. Selv om anfallsaktiviteten kan avta noe i voksen alder, samtidig som anfallene kan endre karakter, preges de fleste pasienter av hyppige anfall og en global encefalopati med kognitiv svikt. Prognosen er fortsatt dyster, både når det gjelder epilepsien og den kognitive utviklingen, men nye farmakologiske og ikke-farmakologiske behandlingsmuligheter kan bedre livskvaliteten hos mange. Ofte er det vanskelig å finne frem til en optimal balanse mellom effekt og bivirkninger. Ved vurdering av pasienter med Lennox-Gastauts syn- drom må man stille seg følgende spørsmål: Foreligger overbehandling, underbehandling eller en uhensiktsmessig behandling?

Oppgitte interessekonflikter: Alle forfatterne har mottatt reisestøtte til epilepsikonferanser og foredragshonorar fra GlaxoSmithKline, UCB Pharma og Eisai.

\section{Litteratur}

1. Lennox WG Davis JP Clinical correlates of the fast and the slow spike-wave electroencephalogram. Pediatrics 1950; 5: 626-44.

2. Gastaut H, Roger J, Soulayrol R et al. Childhood epileptic encephalopathy with diffuse slow spikewaves (otherwise known as «petit mal variant») or Lennox syndrome. Epilepsia 1966; 7: 139-79.

3. Arzimanoglou A, French J, Blume WT et al. Lennox-Gastaut syndrome: a consensus approach on diagnosis, assessment, management, and trial methodology. Lancet Neurol 2009; 8: 82-93.

4. Doose H, Gerken H, Leonhardt R et al. Centrencephalic myoclonic-astatic petit mal. Clinical and genetic investigation. Neuropadiatrie 1970: 2: $59-78$

5. Heiskala H. Community-based study of LennoxGastaut syndrome. Epilepsia 1997; 38: 526-31.

6. Trevathan E, Murphy CC, Yeargin-Allsopp M. Prevalence and descriptive epidemiology of LennoxGastaut syndrome among Atlanta children. Epilepsia 1997: 38: 1283-8.

7. Markand ON. Lennox-Gastaut syndrome Ichildhood epileptic encephalopathy). J Clin Neurophysiol 2003; 20: 426-41.

8. Waaler PE, Blom BH, Skeidsvoll H et al. Prevalence, classification, and severity of epilepsy in children in western Norway. Epilepsia 2000; 41: $802-10$

9. Forsgren L, Edvinsson SO, Blomquist HK et at. Epilepsy in a population of mentally retarded children and adults. Epilepsy Res 1990; 6: 234-48.

10. Selmer KK, Lund C, Brandal K et al. SCN1A mutation screening in adult patients with LennoxGastaut syndrome features. Epilepsy Behav 2009; 16: 555-7.

11. Yagi K. Evolution of Lennox-Gastaut syndrome: a long-term longitudinal study. Epilepsia 1996; 37 (suppl 3): 48-51.

12. Glauser TA. Topiramate in the catastrophic epilepsies of childhood. J Child Neurol 2000; 15 (suppl 1): S14-21.

13. Chatrian GE, Lettich E, Wilkus RJ et al. Polygraphic and clinical observations on tonic-autonomic seizures. Electroencephalogr Clin Neurophysiol Suppl 1982; 35: 101-24.

14. Ikeno T, Shigematsu H, Miyakoshi M et al. An analytic study of epileptic falls. Epilepsia 1985: 26: 612-21.

15. Egli M, Mothersill I, O'Kane M et al. The axial spasm-the predominant type of drop seizure in patients with secondary generalized epilepsy. Epilepsia 1985; 26: 401-15.
16. Beaumanoir A. The Lennox-Gastaut syndrome a personal study. Electroencephalogr Clin Neurophysiol Suppl 1982; 35: 85-99.

17. Aicardi J, Levy Gomes A. Clinical and electroencephalographic symptomatology of the «genuine» Lennox-Gastaut syndrome and its differentiation from other forms of epilepsy of early childhood. Epilepsy Res Suppl 1992; 6: 185-93.

18. Aicardi J. Epileptic syndromes in childhood. Epilepsia 1988; 29 (Suppl 3): S1-5.

19. Trevathan E. Infantile spasms and Lennox-Gastaut syndrome. J Child Neurol 2002; 17 (suppl 2): S9-22.

20. Oguni H. Hayashi K, Osawa M. Long-term prognosis of Lennox-Gastaut syndrome. Epilepsia 1996; 37 (Suppl 3): 44-7.

21. Genton P, Guerrini R, Dravet C. The LennoxGastaut syndrome. I: Meinardi H, red. Handbook of clinical neurology. Bd. 73. The epilepsies part II. Amsterdam: Elsevier Science, 2000: 211-22.

22. Niedermeyer E. Lennox-Gastaut syndrome. Clinical description and diagnosis. Adv Exp Med Biol 2002: 497: $61-75$.

23. Hoffmann-Riem M, Diener W, Benninger $C$ et al. Nonconvulsive status epilepticus-a possible cause of mental retardation in patients with LennoxGastaut syndrome. Neuropediatrics 2000; 31 : 169-74.

24. Nikanarova M, Sabers A, Felazzo E et al. LennoxGastaut syndrome. I: Nikanarova M, Genton P, Sabers A, red. Long-term evolution of epileptic encephalopathies. Surrey: John Libbey, 2009: $51-66$

25. Hancock E, Cross H. Treatment of Lennox-Gastaut syndrome. Cochrane Database Syst Rev 2003; 3 CD003277

26. Glauser T, Kluger G, Sachdeo R et al. Rufinamide for generalized seizures associated with LennoxGastaut syndrome. Neurology 2008; 70: 1950-8.

27. Ferrie CD, Patel A. Treatment of Lennox-Gastaut syndrome (LGS). Eur J Paediatr Neurol 2009: 13: 493-504.

28. livanainen M. Phenytoin: effective but insidious therapy for epilepsy in people with intellectual disability. J Intellect Disabil Res 1998; 42 (suppl 1): $24-31$

29. Brodtkorb E, Aamo T, Henriksen 0 et al. Rectal diazepam: pitfalls of excessive use in refractory epilepsy. Epilepsy Res 1999; 35: 123-33.

30. Dravet C. Lennox-Gastaut syndrome: a surgically remediable epilepsy. I: Lüders HO Comair YG red. Epilepsy surgery. Philadelphia, PA: Lippincott Williams \& Wilkins, 2001: 165-75

31. Kostov K, Kostov H, Taubøll E. Long-term vagus nerve stimulation in the treatment of LennoxGastaut syndrome. Epilepsy Behav 2009: 16: $321-4$

Mottatt 28.12. 2009, første revisjon 28.3. 2010, godkjent 26.8. 2010. Medisinsk redaktør Trine B. Haugen. 